\title{
In-Situ Synthesis of New Electrode Materials for Li-Ions Batteries using a cold FEG Environmental HRTEM.
}

\author{
M.L. Trudeau ${ }^{1}$, J.Y. Howe ${ }^{2}$, R. Veillette ${ }^{1}$, and K. Zaghib ${ }^{3}$ \\ ${ }^{1}$ Materials Science, Hydro-Québec Research Institute, 1800 Boul. Lionel-Boulet, Varennes, Québec, \\ Canada, J3X 1S1 \\ ${ }^{2}$ Hitachi High-Technologies Canada, Rexdale, Ontario, Canada, M9W 6A4 \\ ${ }^{3}$ Energy Storage and Conversion, Hydro-Québec Research Institute, 1800 Boul. Lionel-Boulet, \\ Varennes, Québec, Canada, J3X 1S1
}

Li-ion batteries are emerging as one of the most promising technology for energy storage today. However, in order for this technology to flourish, there is a need to rapidly develop new electrode materials with better properties to ameliorate the overall battery performance.

Conventional synthesis of new electrode materials, involving heat treatment in high-temperature furnaces, followed by materials characterization, is an extremely long process that can easily miss the best set of conditions for the synthesis of particular compounds. Consequently, it is important to develop in-situ techniques to directly observe changes in material structures and chemistry at the nanometer level during synthesis. We have previously demonstrated that for some structural features in carbon coated LiFePO4, observations in vacuum are not representative of the reality and in order to be useful, these real time observations need to be performed under representative atmospheres, such as air, oxygen or nitrogen [1]. Figure-1 presents HAADF images and EDS Ni and Mn combined maps of some Li, Ni, Mn and $\mathrm{O}$ compounds during in-situ thermal annealing up to $900{ }^{\circ} \mathrm{C}$ in vacuum. Contrary to the formation of $\mathrm{LiNi}_{0.5} \mathrm{Mn}_{1.5} \mathrm{O}_{4}$ crystals that is normally the result of ex-situ furnace annealing in air, $\mathrm{Ni}$ and $\mathrm{Mn}$ were found here to phase separate.

Environmental HRTEM is thus needed for characterizing the morphology as well as the crystallographic and chemistry changes that occur during heat treatment because of its high resolution in observing microstructure and chemical features under various atmospheres. We present here some in-situ synthesis of Li batteries electrodes using the new HF-3300 cold FEG Environmental TEM (E-TEM) from Hitachi. The combination of a cold cathode emitter coupled with a high resolution GIF system (Gatan Quantum ER) and a $60 \mathrm{~mm}^{2}$ SDD EDS detector (Bruker X-flash 5060) allows for rapid chemical analyses as materials react in various atmospheres (with up to 6 simultaneous gases). This microscope has shown a resolution of better that $0,2 \mathrm{~nm}$ at $45 \mathrm{kV}$ on gold particles and an energy resolution of $0.30 \mathrm{eV}$ at $300 \mathrm{kV}$ under high brightness conditions.

Figure-2a and $b$ present a STEM (SE) and (BF) micrograph of a small region after the same materials were annealed for less than 15 minutes at $900{ }^{\circ} \mathrm{C}$ in $\sim 40 \mathrm{~Pa}$ of air in this E-TEM. Well defined Ni-Mn-O crystals of the order of 40 to $80 \mathrm{~nm}$ can be easily seen, with the EELS spectrum taken on region 1 presented in Figure-2c. Finally, Figure-3a and b show respectively a STEM (BF) micrograph of two connected nanocrystals and the corresponding combined RGB Ni, Mn and O EELS map.

The difference between in-situ vacuum and air annealing can thus be clearly seen in this case, and demonstrate that environmental HRTEM is an essential tool for the synthesis understanding of the next generation of battery materials. 
[1] M.L. Trudeau, D. Laul, R. Veillette, A.M. Serventi, A. Mauger, C.M. Julien and K. Zaghib, J. Power Source 196, 7383 (2011)
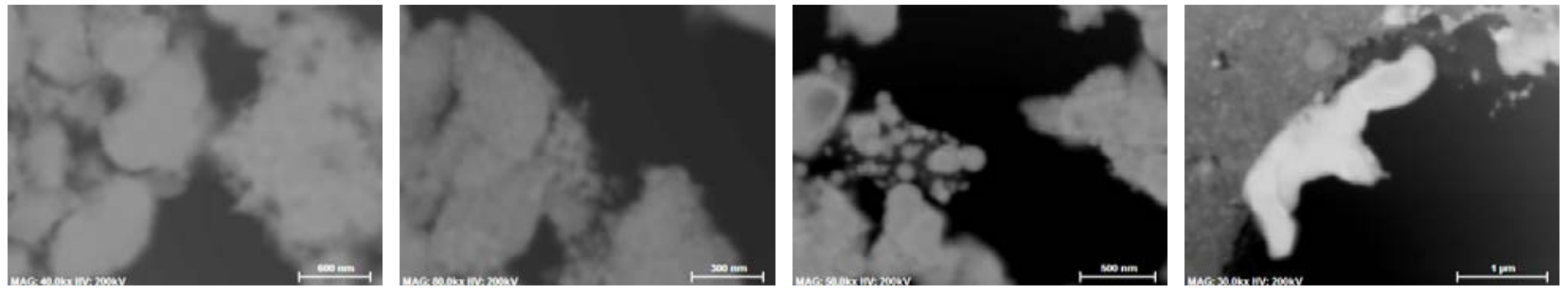

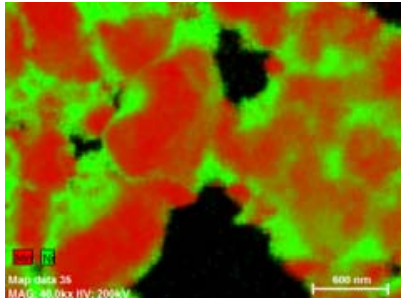

RT

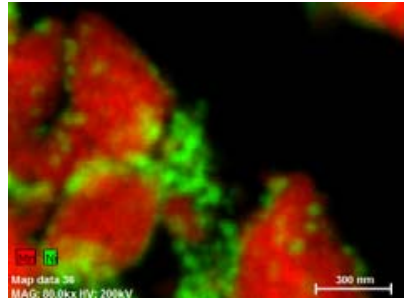

$500{ }^{\circ} \mathrm{C}$

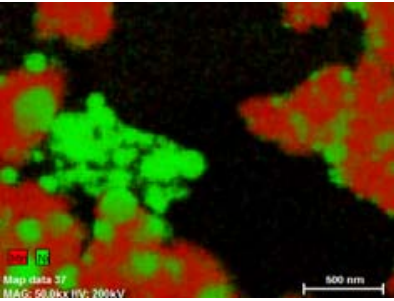

$700{ }^{\circ} \mathrm{C}$

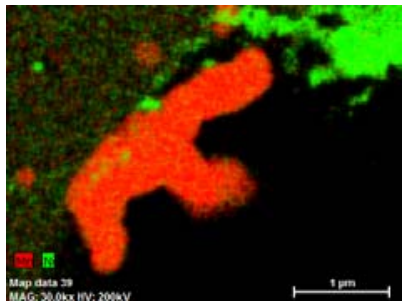

$900{ }^{\circ} \mathrm{C}$

Figure 1. Low Resolution STEM HAADF micrographs with the corresponding combined EDX Ni and Mn during in-situ annealing up to $900{ }^{\circ} \mathrm{C}$ in vacuum of some $\mathrm{Li}, \mathrm{Ni}, \mathrm{Mn}$ and $\mathrm{O}$ compounds.
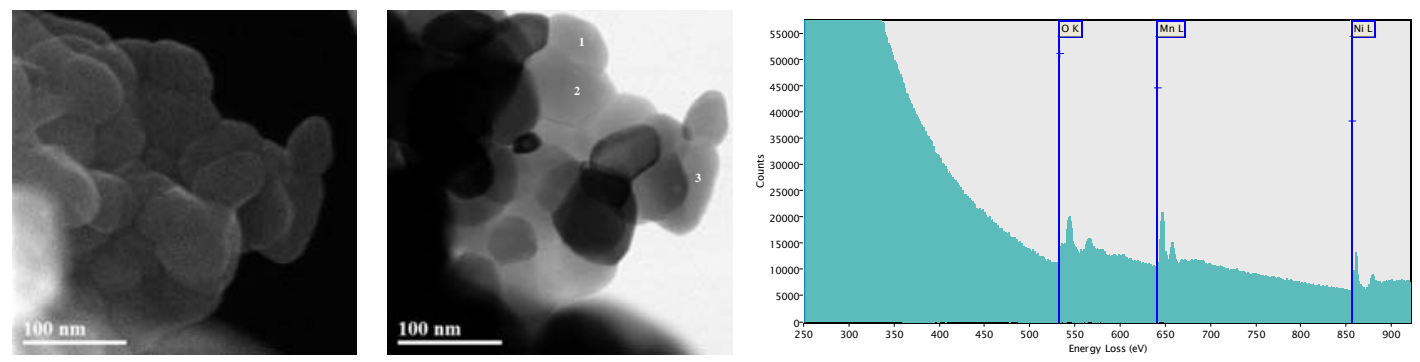

Figure 2. STEM a) SE and b) BF micrograph of a small region after the same material than in Figure-1 was annealed for less than 15 minutes at $900{ }^{\circ} \mathrm{C}$ in $\sim 40 \mathrm{~Pa}$ of air in the E-TEM; c) EELS spectra from region 1. Similar spectra were obtained from the other regions.
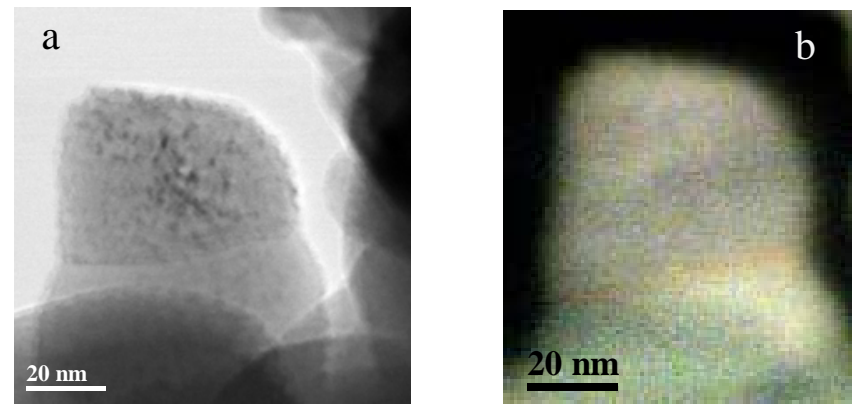

Figure 3. a) Bright Field micrograph of some small crystals after in-situ annealing of $\mathrm{Li}, \mathrm{Ni}, \mathrm{Mn}$ and $\mathrm{O}$ compounds to $900{ }^{\circ} \mathrm{C}$ under $\sim 40 \mathrm{~Pa}$ of air for less than 15 minutes; b) EELS Ni (blue), Mn (red) and $\mathrm{O}$ (green) RGB map for the same region showing quite a good homogeneity. 